Crop Breeding and Applied Biotechnology 15: 139-145, 2015

Brazilian Society of Plant Breeding. Printed in Brazil

\title{
ARTICLE
}

http://dx.doi.org/10.1590/1984-70332015v15n3a25

\section{Crossability and evaluation of incompatibility barriers in crosses between Capsicum species}

Kellen Coutinho Martins ${ }^{1 *}$, Telma Nair Santana Pereira ${ }^{1}$, Sérgio Alessandro Machado Souza ${ }^{1}$, Rosana Rodrigues ${ }^{1}$ and Antônio Teixeira do Amaral Junior ${ }^{1}$

Received 11 February 2014

Accepted 15 October 2014

\begin{abstract}
The objectives of this study were to estimate the crossability rate in combinations of and assess the occurrence of incompatibility barriers between Capsicum species. The species C. annuum, C. chinense, C. frutescens, C. baccatum var. pendulum, and C. baccatum var. baccatum were crossed and the number of hand-pollinations and of resulting fruits and plants was registered. The resulting hybrids were evaluated for their pollen viability and in the crosses that produced no hybrids, the in vivo germination of pollen grains was assessed. Some crosses generated hybrids, while others produced no fruit or, despite generating fruits, no plants grew from them. The crossability rate between species of the complex C. annuum and C. baccatum ranged from $2.2 \%$ to $3.7 \%$, and was $14.6 \%$ between species of the complex C. annuum. A pre-fertilization barrier was observed in the non-germination of pollen grains, as well as post-fertilization barriers consisting of embryo death, lack of vigor and hybrid sterility
\end{abstract}

Key words: Interspecific hybridization, peppers, sweet pepper, germination, pollen grains.

\section{INTRODUCTION}

Interspecific hybridizations allow a transfer of genes of interest between different species, especially those involved in disease resistance (Bosland and Votava 2000), allowing breeders to develop genetically superior genotypes. However, for the success of such a transfer, the species must be genetically close, minimizing problems of incompatibility and thus enabling hybridization. Moreover, it is imperative to know about the direction of the cross, since, in some species, the interspecific cross is possible in one direction only (Prestes and Goulart 1995).

Incompatibility barriers in interspecific crosses may be expressed before fertilization in prezygotic barriers, and/ or after fertilization, in postzygotic barriers. Among the former we can cite the non-germination of pollen grains on the stigma of the receptor plant and a slow pollen tube growth towards the ovule, and among the latter embryo death caused by endosperm degeneration, a lack of vigor and plant sterility of the hybrid plant (Pickersgill 1991, 1992, 1997).

As a general rule, the closer the species involved in the cross are genetically the easier it will be to breed hybrids and the more fertile the progenies (Singh 2002); thus, the existence of barriers in interspecific crosses indicates the genetic distance of species. The genus Capsicum comprises three gene complexes, formed on the basis of crossability between species: 1) Complex C. annuum, C. annuum (varieties annuum and glabriusculum): C. frutescens, C. chinense, C. chacoense and C. galapagoense (Pickersgill 1971, Zijlstra et al. 1991); 2) Complex C. baccatum: C. baccatum (varieties baccatum, pendulum and praetermissum) (Pickersgill 1991, Zijlstra et al. 1991) and C. tovarii (Tong and Bosland 1999); and 3) Complex C. pubescens: C. cardenasii, C. eximium and C. pubescens (Pickersgill 1991, Zijlstra et al. 1991).

The literature reports that interspecific hybrids may be obtained from the genus Capsicum, however, they have varying fertility degrees which may be due to problems of chromosome pairing in hybrids or due to the presence of different chromosomal structural arrangements (Lanteri and Pickersgill 1993, Kumar et al.1987).

Due to the importance of interspecific hybridization for crop improvement, the objectives of this study were to estimate the crossability by breeding interspecific hybrids and

${ }^{1}$ Universidade Estadual do Norte Fluminense Darcy Ribeiro, Centro de Ciências e Tecnologias Agropecuárias, Laboratório de Melhoramento Genético Vegetal, Av. Alberto Lamego, 2000, Parque Califórnia, 28.013-602, Campos dos Goytacazes, RJ, Brazil. *E-mail: kellen.coutinho@hotmail.com 
verify the occurrence of incompatibility barriers manifested in the establishment of these hybrids.

\section{MATERIAL AND METHODS}

The crosses were performed between November 2012 and July 2013, always between 5:30 AM and 7:30 AM. Controlled hand pollinations were performed between parents of the complexes annuum and baccatum: C. annuum (Casca Dura Ikeda), C. chinense (UENF 1785), C. frutescens (UENF 1636), C. baccatum var. baccatum (UENF 1495) and C. baccatum var. pendulum (UENF 1624).

Seeds of these accessions were germinated in a BOD incubator at $27.5^{\circ} \mathrm{C}$, with 8 -h light/16-h dark photoperiods, and then planted in a greenhouse, 10 plants per species. To obtain the $\mathrm{F}_{1}$ hybrids, flower buds were collected from the male parents and pollen grains transferred to the stigma of the plants whose flower buds had been emasculated before pollination. After this procedure, the flowers were protected by a paper bag to avoid contamination with pollen of the other parents and the crosses were labeled.

To evaluate the crossability, the number of crosses was recorded and two days after pollination, the crosses were examined for fruit set. Later, the number of seedless fruits and/or abnormal (empty) seeds was recorded. The fruits were picked and seeds extracted for posterior sowing. The $\mathrm{F}_{1}$ hybrid plants that originated the fruits were described by the descriptors recommended by IPGRI (1995).

The male sterility of the hybrids was assessed by the pollen viability test. To this end, the flower buds in anthesis were collected and fixed in $70 \%$ ethanol. Subsequently, the viability was tested by the triple-stain method of Alexander (1969). Eight slides were mounted on which 250 pollen grains slide ${ }^{-1}$ were recorded as viable (purple) and nonviable (green), counting a total of 2000 pollen grains per hybrid combination.

To identify pre-fertilization barriers, the accessions involved in the crosses that formed no fruits were used for pollinations and selfings and the pollen tube growth observed, as proposed by Dafni (1992). The pistils were collected and stored in FAA (37\% formalin, acetic acid and 70\% alcohol) 24,48 and 72 hours after pollinations and softened in $8 \mathrm{~N}$ sodium hydroxide for 8 hours and stained in a solution of $0.1 \%$ aniline blue diluted in potassium acetate $(0.1 \mathrm{M})$ for 4 hours. Five flower buds per evaluation were collected, totaling 15 buds per parent and hybrid combination. The assessment consisted in the observation of pollen grains germinated on the stigma and in the presence of pollen tubes on the style and in the ovary.

Table 1. Number of pollinated flowers (NPF), number of fruits with seeds (NFWS) and number of adult plants (NAP) and pollen viability of hybrids (\% VP) obtained in the combinations

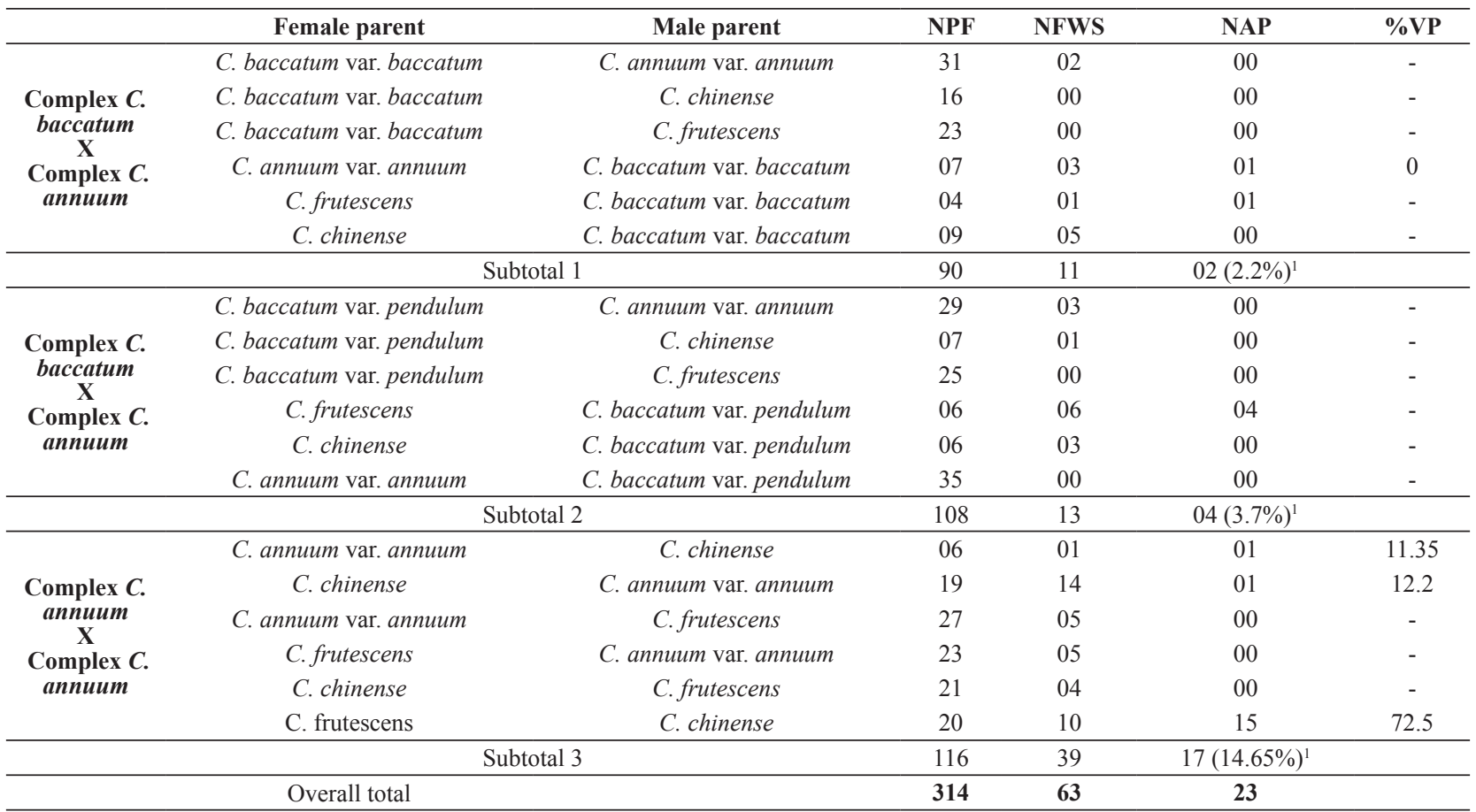




\section{RESULTS AND DISCUSSION}

Based on the results, the presence of pre- and postfertilization barriers was identified in crosses between Capsicum species. Of the 314 hand pollinations, 63 fruits with seeds were obtained, corresponding to a $20.06 \%$ fruiting rate. Some combinations produced fruits that generated no plants, others generated plants and fruits and some bore no fruits, and consequently no plants (Table 1).

The crossability rate between species of the complexes C. annuum and C. baccatum ranged from $2.2 \%$ to $3.7 \%$. In the crosses involving $\mathrm{C}$. baccatum var. baccatum as pollen receptor, two fruits with seeds (C. baccatum var baccatum $\mathrm{x}$ C. annuum var. annuum) were obtained, from which however no plants could be grown. In the inverse direction, nine fruits were produced of which in the end only two hybrid plants reached adulthood (C. annuum var. annuum x C. baccatum var. baccatum; C. frutescens x C. baccatum var. baccatum). The number of plants obtained from combinations involving C. baccatum var. pendulum was higher than that of crosses of C. baccatum var. baccatum, since of the 13 fruits with seeds, 04 hybrids grew to adult plants (Table 1).

One of the most frequent post-fertilization barriers in crosses between species of the two gene complexes was fruit formation with abnormal seeds, with sizes differing from those of the parents and dark-colored, indicating degeneration and death. Empty or degenerated seeds are considered post-fertilization barriers in most crosses (Jansky 2006), possibly involving endosperm degeneration and subsequent death of the embryo (Rodrangboon et al. 2002).

According to Pickersgill (1991), embryo abortion is a common feature in interspecific Capsicum crosses. The endosperm develops more slowly than normal, delaying the embryo development and after about two weeks, the embryonic sac collapses (Pickersgill 1997). Yoon et al. (2006) observed that in C. annuum x C. baccatum crosses, embryo abortion occurs 15 days after pollination, representing the first genetic barrier to hybridization between the species.

Another anomaly was the drying of pollinated fruits while still on the mother plant; this abnormality was observed in the cross C. baccatum var. pendulum $\mathrm{x}$ C. annuum var. annuum, where four of the eight fruits dried before the beginning of maturing and contained no seeds. The other fruit resulting from the cross that did not reach maturity was lost when still green, but had a normal appearance.

Among the post-fertilization barriers that occur in interspecific crosses, one can mention hybrid weakness or necrosis. This anomaly is defined by a series of phenotypic characteristics that are similar to those associated with response to environmental stress, such as attack of pathogens and viral diseases (Bomblies and Weigel 2007). This type of expression was observed in hybrids of the combination C. frutescens x C. baccatum (both varieties) (Figure 1), in the seedling as well as adult stage; in addition, some seedlings that did not develop died young and had deformed cotyledons, with stunted development. The 05 adult hybrid plants grown from these combinations produced no flowers and consequently no fruit.

According to Yazawa et al. (1989), hybrids with abnormal growth and shriveling of the leaves are typical features in crosses of these two species. These mutant plants appear spontaneously due to a possible mutagenic effect of interspecific hybridization, but the environment can also contribute to the emergence of this anomaly (Csilléry 2013).

It was also observed that when C. frutescens was used as female parent, and both C. baccatum varieties were used as pollen donors, most pollinations produced fruit, while in the opposite direction this was not the case (Table 1). This behavior may be interpreted as unilateral incompatibility. Unilateral incompatibility occurs when pollen tubes reach and fertilize the ovules in a cross in one direction but are inhibited in the stigma, style or ovary in the reciprocal cross (Onus and Pickersgill 2004). Bapa Rao et al. (1992) obtained hybrid combinations from crosses between C. baccatum var. pendulum and $\mathrm{C}$. frutescens and reported unilateral
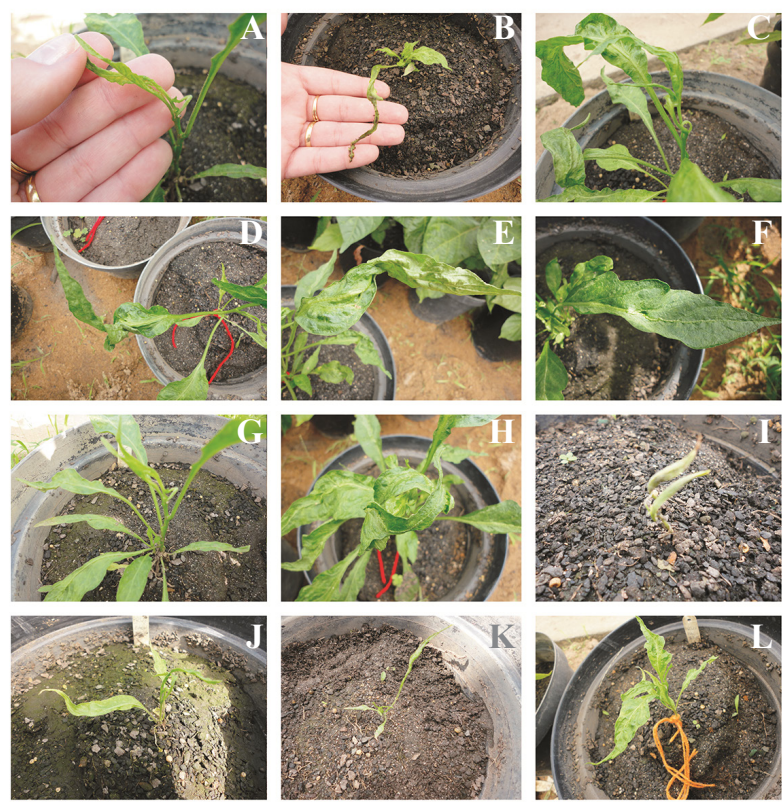

Figure 1. Abnormal appearance of hybrid plants obtained from crosses between $C$. frutescens x $C$. baccatum var. pendulum $(\mathrm{A}-\mathrm{H})$ and $C$. frutescens $\mathrm{x} C$. baccatum var. baccatum (I-L). 
incompatibility as well, although in this case, inter-specific hybrids were only established when the species $\mathrm{C}$. baccatum was used as female parent.

Between the species of the complex annuum, the crossability rate within the complex was $14.65 \%$, and 116 controlled pollinations were performed and 39 fruits with seeds and 17 plants obtained, 15 of which from crosses between $\mathrm{C}$. chinense $\mathrm{x} \mathrm{C}$. frutescens (Table 1).

In the crosses between species of C. annuum var. annuum and C. frutescens, 50 pollinations resulted in 18 fruits. Of these, 10 reached maturity, five fruits from each cross direction, although none of the 368 seeds obtained in the cross C. annuum var. annuum $\mathrm{x}$ C. frutescens germinated. Cheng et al. (2007) also obtained fruits with seeds in both directions of the cross between these two species, which were however unviable. Smith and Heiser (1951) found that when C. frutescens was used as female parent, the seed germination percentage of this cross was low and when C. annuum var. annuum was used as female parent, the seeds did not germinate.

Although 15 fruits were produced in the crosses between the species $C$. annuum var. annuum and $C$. chinense, this resulted in only two adult plants (Table 1), since most of the seeds had abnormal shape and color and did not germinate. The other seeds that germinated grew no primary leaves and did not survive. In both combinations, all fruits were red, regardless of the cross direction, indicating that the red color of C. annuum var. annuum predominates over the orange color of $\mathrm{C}$. chinense.

Costa et al. (2009) evaluated the compatibility of the cross between C. annuum and C. chinense (Casca Dura Ikeda) and seed vigor and germination of the interspecific hybrids. The authors reported that all interspecific crosses bore fruit, with fruiting rates ranging from $8.9 \%$ to $40.0 \%$ and seed germination from $0.0 \%$ to $87.5 \%$.

Among the species of the complex annuum, the most successful combination was $C$. frutescens $x \mathrm{C}$. chinense. Of the total of 12 fruits from C. chinense x C. frutescens, only four reached maturity and produced seeds, of which six germinated, but did not reach adulthood. However, when $\mathrm{C}$. frutescens was used as female parent, 10 mature fruits were obtained, which together produced 48 seeds that ultimately resulted in 15 adult plants. Similarly to the above results, the success with $\mathrm{C}$. frutescens was greatest when the species was used as female parent, which shows that this performance does not depend on whether the crosses are made between gene complexes or within the same complex.

The cross between the species $\mathrm{C}$. chinense and $\mathrm{C}$. frutescens is considered possible for being the closest species within the complex C. annuum (Pickersgill 1991). Despite the field losses, 14 fruits with seeds were derived from 41 pollinations, showing the proximity of the species.

Examples of natural and artificial hybridization between $\mathrm{C}$. chinense and $\mathrm{C}$. frutescens have been reported. Cultivar Greenleaf Tabasco was developed by interspecific hybridization between these two species, followed by repeated backcrossing with $\mathrm{C}$. frutescens (Greenleaf et al. 1970). Bosland and Baral (2007) however recently reported that "Bhut Jolokia", the world's hottest pepper, with an official Scoville heat rating (SHU) of 1,001,304, is a natural interspecific hybrid between $\mathrm{C}$. chinense and $\mathrm{C}$. frutescens.

The 15 hybrid plants derived from the combination C. frutescens x C. chinense had intermediate characteristics between the parents in terms of anther color and fruit weight, length, width, thickness, and shape, although the fruit shape was similar to that of the female parent. The height and width of the hybrid plants were superior to those of the parents in all cases (Table 2).

After establishing the crosses and recording the absence of fruit production in the combinations $\mathrm{C}$. annuum var. annuum x C. baccatum var. pendulum, C. baccatum var. baccatum $x C$. frutescens and $C$. baccatum var. pendulum $x$ C. frutescens, the pollen tube growth of these combinations and the parents was examined. The combination of $\mathrm{C}$. annuum var. annuum $x \mathrm{C}$. chinense was not included in this analysis since four fruits were obtained, however failed to reach maturity.

Table 2. Characterization of hybrid plants of crosses between $C$. frutescens $\mathrm{x} C$. chinense

\begin{tabular}{llll}
\hline Traits & C. frutescens & C. chinense & Hybrid \\
\hline Anther color & Clear blue & Purple & Light purple \\
Plant height $(\mathrm{cm})$ & $66-85$ & $66-85$ & $<85$ \\
Plant width $(\mathrm{cm})$ & 65.2 & 73.2 & 84.7 \\
Fruit length $(\mathrm{mm})$ & 25.58 & 47.96 & 29.39 \\
Fruit width $(\mathrm{mm})$ & 5.91 & 28.871 & 9.996 \\
Average fruit weight $(\mathrm{g})$ & 0.52 & 11.57 & 1.14 \\
Fruit wall thickness $(\mathrm{mm})$ & 0.578 & 2.822 & 1.242 \\
\hline
\end{tabular}


In the selfings used as a control, no incompatibility was detected, since 48 hours after pollination the pollen grains had already reached the ovules in C. annuum var. annuum (Figure 2B) and the ovary in $\mathrm{C}$. baccatum var. baccatum (Figure 2D).

In the cross of the species $\mathrm{C}$. annuum var. annuum $\mathrm{x}$ C. baccatum var. pendulum, similarly to the selfing of C. annuum var. annuum, the germinated pollen tubes reached the ovules 48 hours after fertilization (Figure 2F). This shows that there is no incompatibility preventing the growth of the pollen tube, and that the failure of the cross between these two species is most likely due to post-fertilization barriers.

Yoon et al. (2006) and Zijlstra et al. (1991), the latter of which studied four accessions of C. baccatum of which two were C. baccatum var. pendulum, found no barrier either to pollen grain germination on the stigma or to pollen tube growth in the style in interspecific combinations of $\mathrm{C}$. annuum and $\mathrm{C}$. baccatum.

The crosses between the species C. frutescens and C. baccatum and their varieties were less sucessful. In both cross directions, the pollen grains germinated 24 hours after pollination (Figure $2 \mathrm{G}$ and $2 \mathrm{~J}$ ) and 48 hours later, it was possible to observe the pollen tubes in the style (Figure $2 \mathrm{H}$ and $2 \mathrm{~K}$ ). However, 72 hours after performing the cross, the pollen tubes were still on the stigma and failed to reach the ovary ((Figure $2 \mathrm{I}$ and $2 \mathrm{~L})$.

Interspecific fertilization often fails because the pollen tubes are incompatible with the pistil and stop growing before reaching the ovules (Pickersgill 1993). This is probably the case of the two C. baccatum varieties, when used as female parents in crosses with $C$. frutescens, indicating that the failure of these crosses may be due to the pre-fertilization barrier in the stage of pollen tube germination.

The 23 interspecific hybrids were evaluated for pollen viability (Table 1). Based on this evaluation, it was observed that in all combinations, except for $\mathrm{C}$. frutescens $\mathrm{x} C$. chinense with a viability of $72.5 \%$, the pollen viability was low and the hybrids were considered sterile or nearly sterile, due to the large number of non-viable pollen grains. The pollen viability of most hybrids can be considered low, mainly when compared with values reported for the species used as parents close to or higher than 90\% (Lanteri and Pickersgill 1993, Martins et al. 2010).

These results indicate that the formation of little or no fruit in hybrids may possibly be directly related to the viability of the male gametophyte. The barrier of hybrid infertility is given by the abnormal development of the male gametophyte, which causes pollen abortion (Yoon
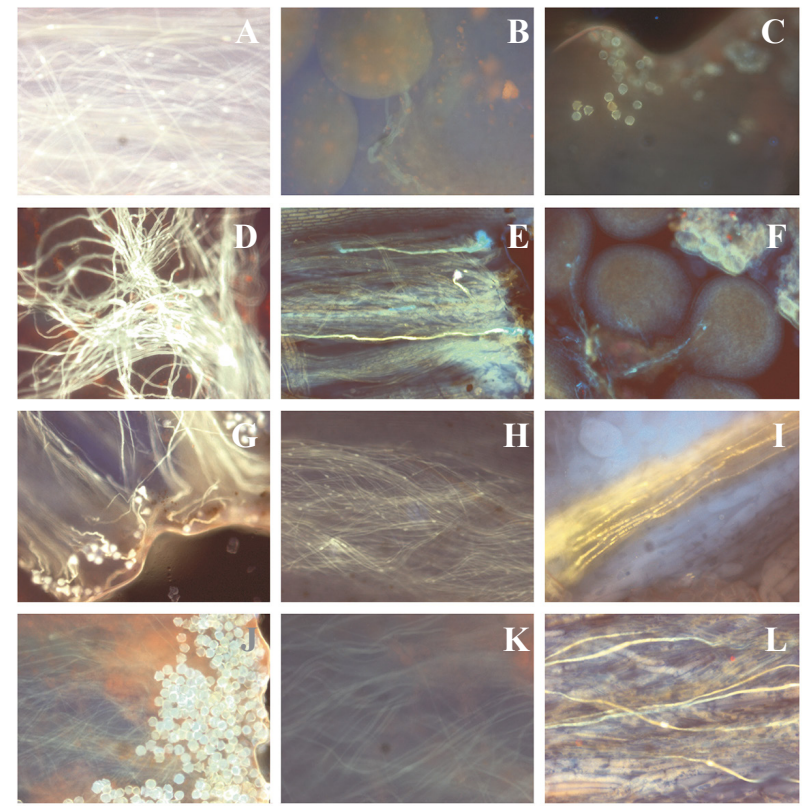

Figure 2. Germination of the pollen tube in vivo in $C$. annuum var. annuит $(\mathrm{A} ; \mathrm{B}) ;$ C. baccatum var. pendulum $(\mathrm{C} ; \mathrm{D}) ;$ C. annuum var. annuum x $C$. baccatum var. pendulum $(\mathrm{E}, \mathrm{F}) ; C$. baccatum var. baccatum x $C$. frutescens $(\mathrm{G}, \mathrm{H}, \mathrm{I}) ;$ C . baccatum var. pendulum $\mathrm{x} C$. frutescens $(\mathrm{J}, \mathrm{K}, \mathrm{L}) . \mathrm{A})$ Pollen tube at the end of the style after 24 hours; B) reaching the ovules after 48 hours; C) no germination after 24 hours; D) at the end of the style after 48 hours; E) pollen tubes on the style 24 hours after pollination; F) reaching the ovules 48 hours after pollination; $\mathrm{G})$ pollen tube germinating in the stigma after 24 hours; (H, I) on the style after 48 and 72 hours, respectively; J) pollen tube germinating in the stigma after 24 hours and; $(\mathrm{K}, \mathrm{L})$ on the style after 48 and 72 hours, respectively.

and Park 2005).

No viable pollen grains were detected in the cross between the species $\mathrm{C}$. annuum var. annuum and $\mathrm{C}$. baccatum var. baccatum (Casca Dura Ikeda x UENF 1495). For belonging to different complexes (Pickersgill 1991), their hybrids have a certain degree of sterility. However, according to Monteiro et al. (2011), fertile hybrids of C. annuum var glabriusculum and C. baccatum var. pendulum were obtained, with pollen viability exceeding $90 \%$. On the other hand, the pollen fertility of the hybrids resulting from reciprocal crosses was low (around 35\%), which was also the case with hybrid combinations of C. baccatum var. baccatum and $\mathrm{C}$. annuum var. annuum.

Several meiotic abnormalities were observed by Yoon and Park (2005), e.g., the formation of univalents, quadrivalents and hexavalents in the mother cells of pollen grain of the hybrids between these two species. In addition, irregular disjunction and lagging chromosomes were also observed, indicating that the direct cause of male sterility is the meiotic abnormalities found in $\mathrm{F}_{1}$ hybrids. 
The pollen viability of hybrids from the species $\mathrm{C}$. annuum var. annuum and $\mathrm{C}$. chinense was on average $11.35 \%$ (C. annuum var. annuum $x$ C. chinense) and $12.2 \%$ (C. chinense x C. annuum var. annuum), suggesting that these plants are sterile or produce very few viable pollen grains. Monteiro et al. (2011) reported a pollen viability of the hybrids of these two species between 34 and $87 \%$. The low values found in this study were not expected, since both species belong to the same gene complex, however, spontaneous translocations were observed between $\mathrm{C}$. annuum and C. chinense, which can generate unbalanced and therefore unviable gametes (Moscone 1990).

\section{REFERENCES}

Alexander MP (1969) Differential staining of aborted non aborted pollen. Stain Techonology 44: 117-122.

Bapa Rao N, Sri Valli T and Lakshmi N (1992) Cytogenetic studies on the interspecific hybrid Capsicum baccatum L, C. frutescens L. and its progeny. Euphytica 59: 135-140.

Bomblies K and Weigel D (2007) Hybrid necrosis: autoimmunity as a potential gene-flow barrier in plant species. Nature Reviews Genetics 8: $382-393$

Bosland PW and Baral JB (2007) 'Bhut Jolokia' - The world's hottest known chili pepper is a putative naturally occurring interspecific hybrid. Hortscience 42: 222-224.

Bosland PW and Votava EJ (2000) Peppers: vegetable and spice Capsicums. CAB International, Wallingford, 204p.

Cheng Zhi-Fang, Quian Chun-Tao, Chen Xue-Jun and Chen Jin-Feng (2007) Interspecific hybridization and identification of hybrid in Capsicum. Acta Horticulturae Sinica 34: 883-888.

Costa LV, Lopes R, Lopes MTG, Figueiredo AF, Barros WS and Alves SRM (2009) Cross compatibility of domesticated hot pepper and cultivated sweet pepper. Crop Breeding and Applied Biotechnology 9: $37-44$.

Csilléry G (2013) Introducing a collection of generative organ pepper mutants. In Lanteri S and Rotinio GL (eds) Proceedings of the XV EUCARPIA meeting on genetics and breeding of capsicum and eggplant. COE, Torino, p. 215-222.

Dafni A (1992) Pollination ecology: a practical approach. Oxford University Press, New York, 250p.

Greenleaf WH, Martins JA, Lease JG, Sims ET and VanBlaricom LO (1970) Greenleaf Tabasco, a new tobacco etch virus resistant "Tabasco" pepper variety (Capsicum frutescens L.). Leaflet. Alabama Agricultural Experiment 81: 1-10.

IPGRI (1995) Descriptors for capsicum (Capsicum spp). IPGRI, Roma, $51 \mathrm{p}$.

Jansky S (2006) Overcoming hybridization barriers in potato. Review Plant Breeding 125: 1-12.
Based on these results, it can be concluded that interspecific hybridization of Capsicum species is hampered by the presence of pre-fertilization barriers such as unilateral incompatibility with the non-germination of pollen grains in the combination $\mathrm{C}$. frutescens $\mathrm{x}$ C. baccatum (both varieties) and post-fertilization barriers with the formation of abnormal/empty seeds, lack of vigor and hybrid sterility.

\section{ACKNOWLEDGEMENTS}

The authors thank the Foundation for Research Foundation of the State of Rio de Janeiro (FAPERJ) for the scholarship of the first author.

Kumar OA, Panda RC and Rao KGR (1987) Cytogenetic studies of the $\mathrm{F}_{1}$ hybrids of Capsicum annuum with $\mathrm{C}$. chinense and C. baccatum. Theoretical and Applied Genetic 74: 242-246.

Lanteri S and Pickersgill B (1993) Chromosomal structural changes in Capsicum annuum L. and Capsicum chinense Jacq. Euphytica 67: $155-160$

Martins KC, Pereira TNS, Souza SAM and Costa FR (2010) Meiose e viabilidade polínica em acessos de Capsicum annuum e Capsicum baccatum. Ciência Rural 40: 1746-1751.

Monteiro CES, Pereira TNP and Campos KP (2011) Reproductive characterization of interspecific hybrids among Capsicum species. Crop Breeding and Applied Biotechnology 11: 241-249.

Moscone EA (1990) Chromosome studies on Caspcium (Solanaceae) I. Karyotype analysis in C. chacoense. Brittonia 42: 147-154.

Onus AN and Pickersgill B (2004) Unilateral incompatibility in Capsicum (Solanaceae): Occurrence and taxonomic distribution. Annals of Botany 94: 289-295.

Pickersgill B (1997) Genetic resources and breeding of Capsicum spp. Euphytica 96: 29-133

Pickersgill B (1993) Interspecific hybridization by sexual means. In Hayward MB, Bosemark NO and Romagosa I (Eds) Plant breeding series; Plant breeding: principles and prospects. Chapman and Hall, London, p. 63-78.

Pickersgill B (1992) Barriers to interspecific gene exchange in Capsicum. In Belletti P and Quagliotti L (eds) Proceedings of the VIII meeting of genetics and breeding on Capsicum and eggplant. Capsicum Newsletter, Rome, p. 57-60.

Pickersgill B (1991) Cytogenetics and evolution of Capsicum L. In Tsuchiya T and Gupta PK (eds) Chromosome engineering in plants: genetics, breeding, evolution, part B. Elsevier, Amsterdam, p.139-160.

Pickersgill B (1971) Relationship between weedy and cultivated forms in some species of chilli peppers, (genus Capsicum). Evolution 25: 683-691.

Prestes AM and Goulart LR (1995) Transferência de resistência a doenças de espécies silvestres para espécies cultivadas. Revisão Anual de Patologia de Plantas 3: 315-363. 
Rodrangboon P, Pongtongkan P, Suputtitaba S and Adachi T (2002) Abnormal embryo development and efficient embryo rescue in interspecific hybrids. Breeding Science 52: 123-129.

Singh RJ (2002) Plant cytogenetics. CRC Press, London, 488p.

Smith PG and Heiser CB (1951) Taxonomic and genetic studies on the cultivated peppers, Capsicum annuum L. and C. frutescens L. American Journal of Botany 38: 362-368.

Tong N and Bosland PW (1999) Capsicum tovarii, a new member of the Capsicum baccatum complex. Euphytica 109: 71-77

Yazawa S, Suetome N, Okamoto K and Namiki TJ (1989) Journal of the Japanese society for horticultural science 58: 601-607
Yoon JB, Yang DC, Wahhng JD and Park HG (2006) Overcoming two post-fertilization genetic barriers in interspecific hybridization between $\mathrm{C}$. annuum $\mathrm{L}$ and $\mathrm{C}$. baccatum $\mathrm{L}$ for introgression of anthracnose resistance. Breeding Science 56: 31-38.

Yoon JB and Park HG (2005) Trispecies bridge crosses, (Capsicum annuum $\mathrm{x}$ C. chinense) x C. baccatum, as an alternative for introgression of anthracnose resistance from C. baccatum into C. annuum. Journal Korean Society for Horticultural Science 46:5-9.

Zijlstra S, Purimahua C and Lindhout P (1991) Pollen tube growth in interspecific crosses between Capsicum species. HortScience 26: 585-586. 